\title{
ESTABLISHING THE OPTIMAL SOLUTION FOR OBSTACLE CROSSINGS. APPLICATION FOR BRIDGE KM.14+162 PLACED ON THE BYPASS OF BISTRITA CITY
}

Radu Adrian IORDANESCU - Ph.D. Eng. Technical University of Civil Engineering Bucharest, e-mail: r_iordanescu@yahoo.com

\begin{abstract}
The Bistrita city bypass crosses obliquely at $\mathrm{km} \mathrm{14+162}$ the Bistrita river and a local road. In the area where the bridge is situated the river has a width of about $50.00 \mathrm{~m}$ and the local road has $5.00 \mathrm{~m}$, being located at $12.00 \mathrm{~m}$ from the bank of Bistrita. The bridge should provide a roadway that is $7.80 \mathrm{~m}$ wide and two sidewalks of $1.50 \mathrm{~m}$.

The challenge is to design a bridge that allows the crossing of the two barriers (the river and the local road) in the most efficient way possible from an economical point of view, but in such a way that both the geometrical constraints and the design requirements contained in the family of the European standards Eurocodes are respected.

In order to achieve this goal, the author has investigated the design situation by comparing different possible technical solutions, by conducting a series of parametric studies and by utilizing mathematical optimization techniques.
\end{abstract}

Following these investigations a $100.00 \mathrm{~m}$ long bridge resulted. The superstructure is a continuous beam with three spans: $20.00 \mathrm{~m}+60.00 \mathrm{~m}+20.00 \mathrm{~m}$ and consists of a composite steel - concrete deck. The deck cross section is composed of two steel beams with variable height and a reinforced concrete slab disposed on top. This configuration of the superstructure leads to the development of negative reaction forces in the bearings located at the end points of the deck.

The study has covered 8 key steps as follows:

- Establishing the technical solution.

- Establishing the number and the length of the spans.

- Setting the static scheme.

- Determining the optimal cross section of the steel beams.

- Setting longitudinal beam geometry.

- Establishing the number of beams in the cross section.

- Determining the optimal mounting order of the concrete slabs.

- $\quad$ Establishing the optimal type and distribution of the bearing devices.

Keywords: composite structure, negative reaction forces, continuous variable beam, optimization

\section{Introduction}

In practice bridge designers rely on their personal or collective experience or on previous research and established rules in order to realize an efficient structure.

Unfortunately despite being helpful in providing a framework none of these forms of knowledge are absolute in every design situation nor in every geographical region nor even constant in time. This being because, for example, that every advance in theory or technology, every change in prices and price ratios like concrete price versus steel price or material price versus labor price and changes in codes of practice or national norms can render an almost optimal design in one situation to become useless in another situation. There are numerous practical examples of this kind of uncertainty taking place, one of them being the Feasibility Study of the Romanian 100km 
highway from Targu Neamt to Ditrau[1] which traverses the Oriental Carpathian mountains and is said to become one of the most expensive roads in the world. The Feasibility Study was conducted by S.C. IPTANA S.A. and was finished in 2011 from which resulted a total number of 84 bridge structures from which 64 were simple supported prestressed concrete beams and the other 20 were composite steel-concrete structures. The next year in 2012 all the structures were reevaluated and the results differed considerably from those in the previous year with only 44 of the structures being simple supported prestressed concrete beams and 40 composite structures, this being in principal due to the introduction of the Eurocodes.

With today's technology and knowhow the only possibility of designing the most efficient structure in a given situation is to compare, analyze and optimize every aspect of that design situation, in other words a complete research is needed to accomplish this task. Of course, in practice, there are time restraints for the projects completions so that design engineers can rarely engage in such a complex undertaking.

The solution for this problem is to standardize the optimization process, to determine which aspects are relevant and which are not and to identify the required tools in order to simplify the task so that it can be incorporated into the design process and later on, in the future, maybe, the development of technologies such as automated algorithms and dedicated software will be possible.

The scope of this paper is to provide an example of such an optimization process in the form of an application for the bridge over the Bistrita river on the Bistrita city bypass on km.14+162 [2]. This particular example was chosen for 2 main reasons, that of supporting a standard 7,80m wide roadway plus 2 sidewalks $1,50 \mathrm{~m}$ each and because of the imposed length of the main span of $60.00 \mathrm{~m}$ which represents a span domain where there is no standard solution and every engineer seems to have a different solution, see figure 1 .

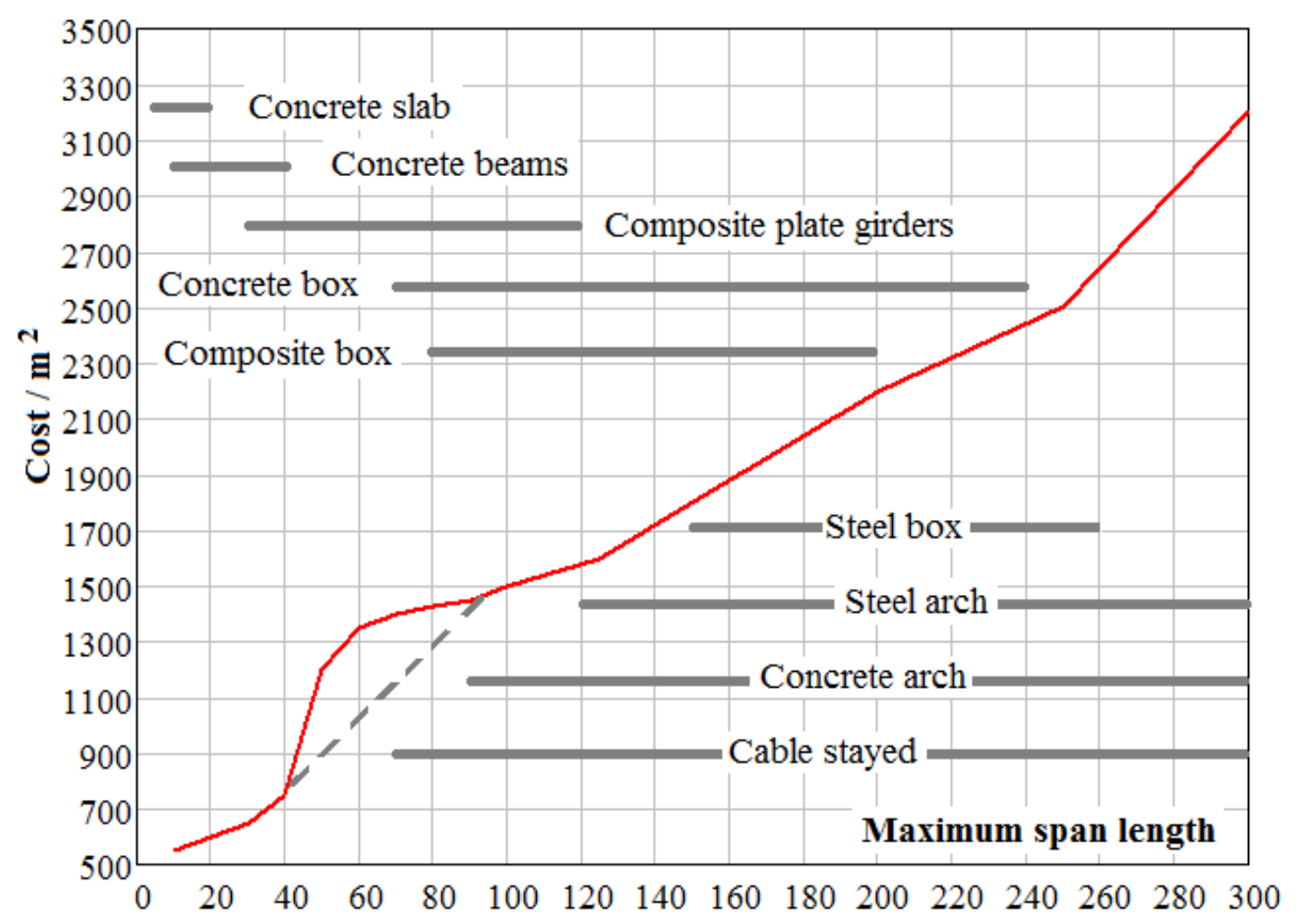

Fig. 1 - Cost $/ \mathrm{m} 2$ vs. span length and the corresponding structure types

From figure 1 is interesting to note the sudden leap in prices from $40 \mathrm{~m}$ onward, the span length corresponding to the maximum length of the concrete beams. 


\section{Establishing the technical solution}

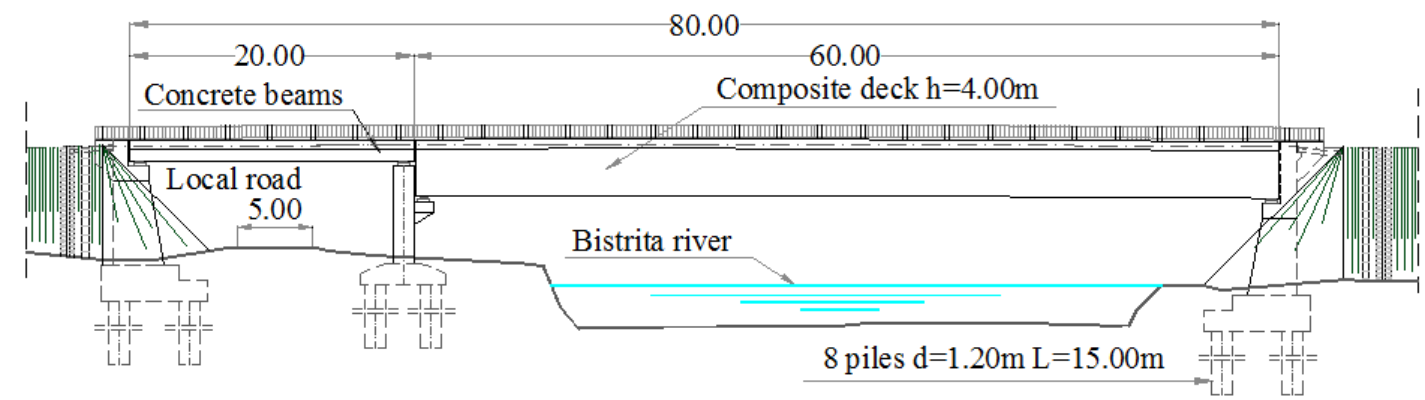

Fig. 2 - Simple supported composite beam

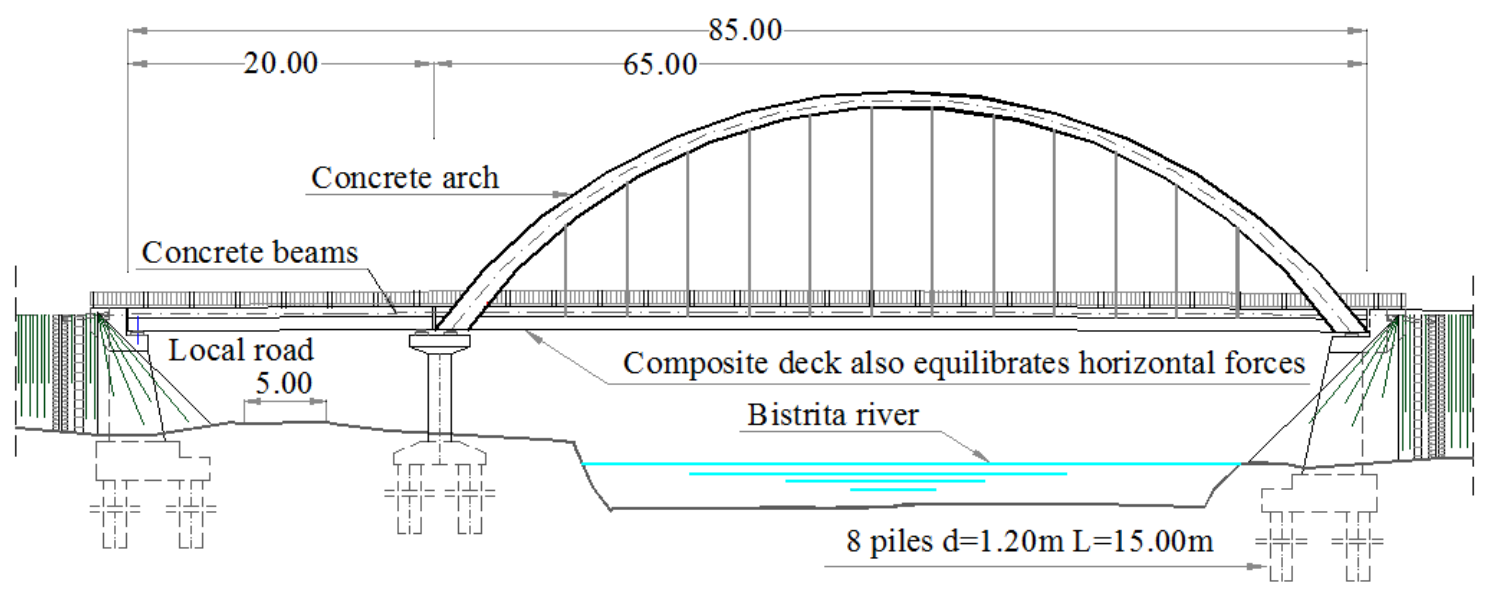

Fig. 3 - Concrete arch with composite deck

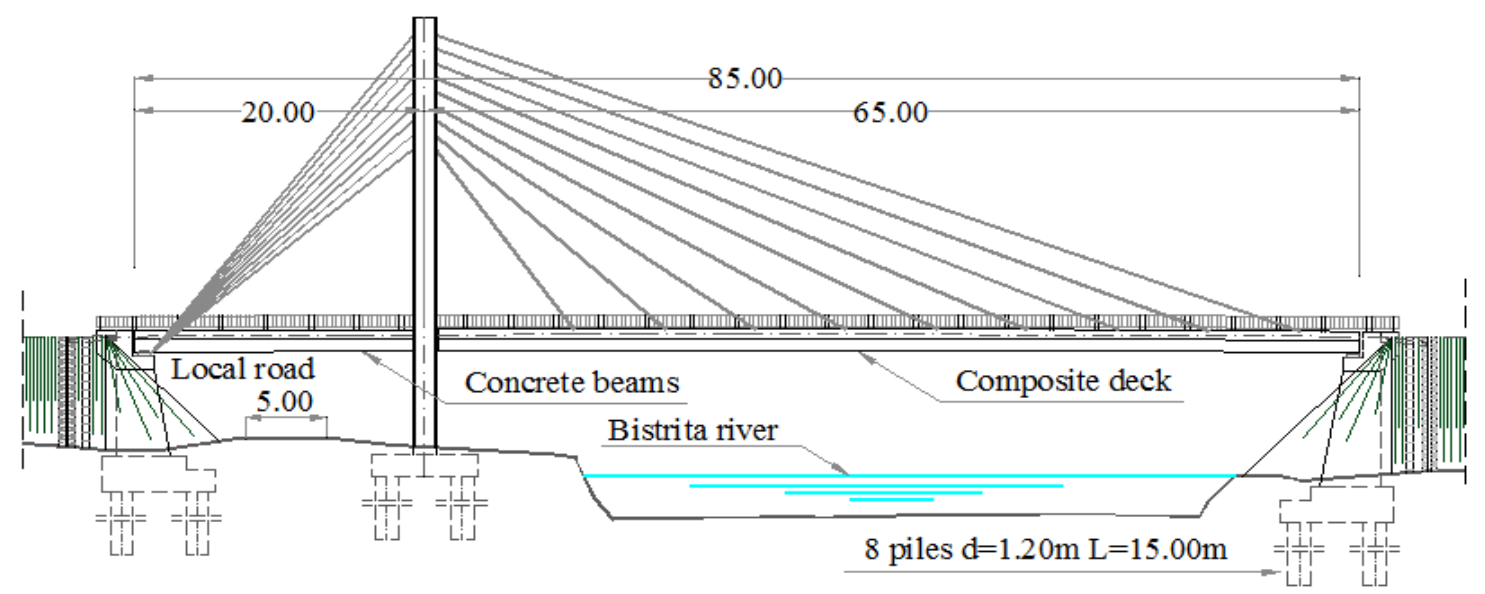

Fig. 4 - Cable stayed with composite deck

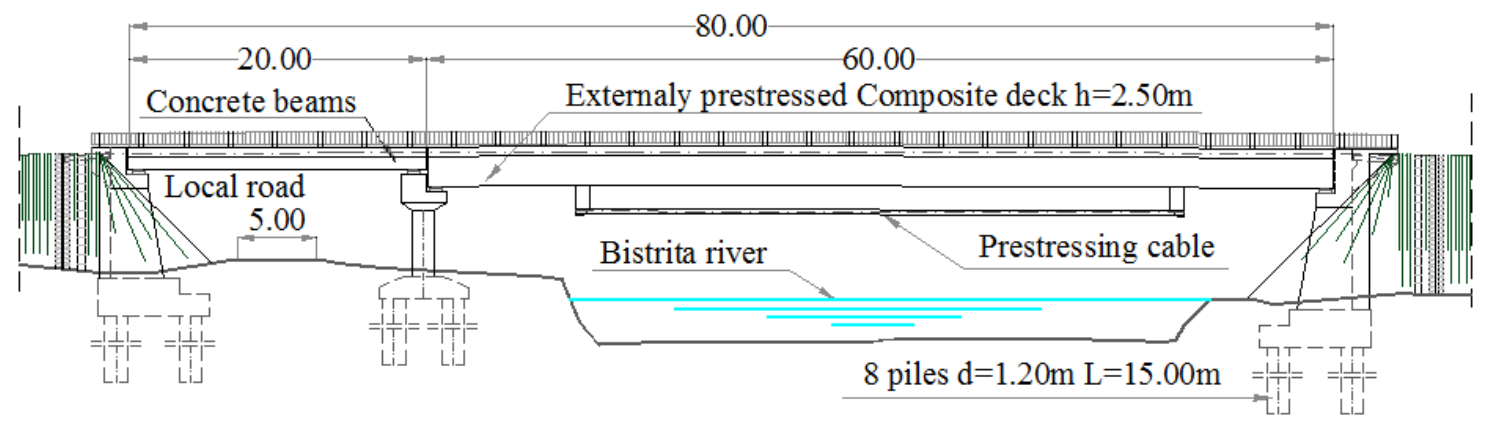

Fig. 5 - External prestressed simple supported composite beam 


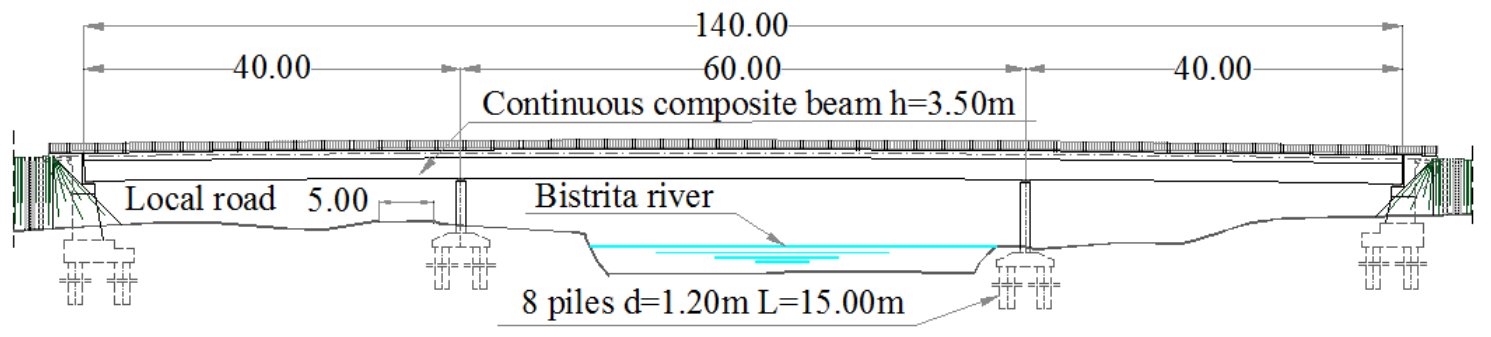

Fig. 6 - Continuous composite beam

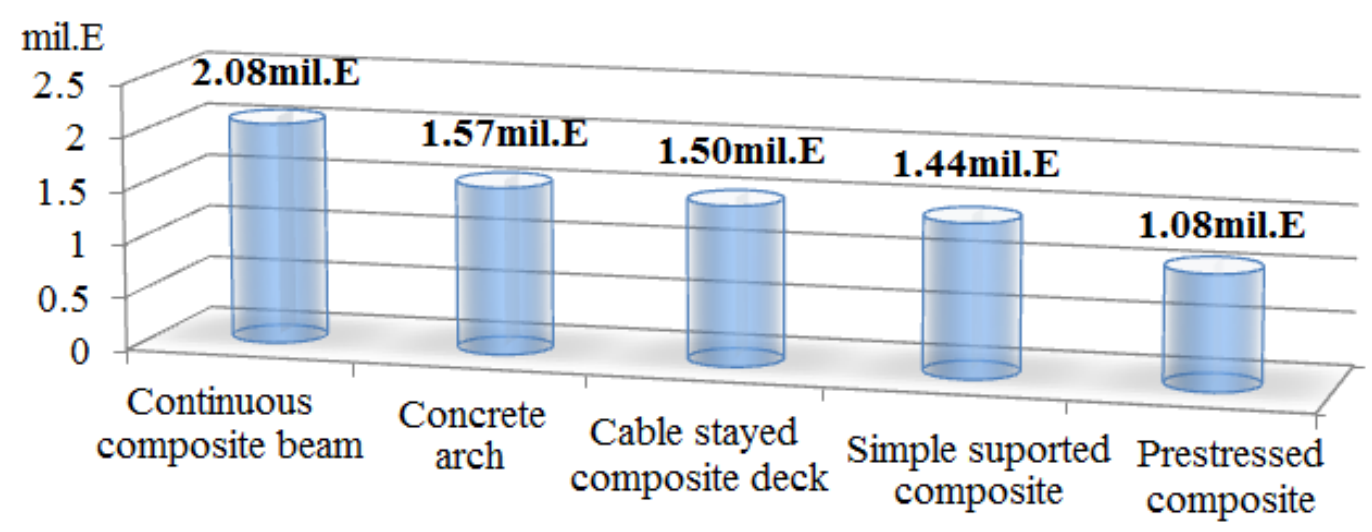

Fig. 7 - Total cost by type of structure

These 5 types of structures were analyzed. The simple supported composite beam is inefficient in terms of stress distribution (it is more efficient to have axial solicitation than bending moments). The concrete arch is more efficient in this regard but although the material volumes decreased the total cost increased because of the more complex execution. The cable stayed is very efficient in terms of stress distribution and also in material consumption but its execution makes it expensive overall. The external prestressed composite beam was found to be very efficient in all respects, but unfortunately, because of its very flexible and slim beams did not met the Eurocod's fatigue requirements [3][4] (further research is needed). The continuous composite beam was found to be the second most efficient structure (figure 8) but in order to obtain the evenly distributed bending moment it needs a certain length $(40 m+60 m+40 m)$ over 3 spans which makes it the most expansive in terms of total cost.

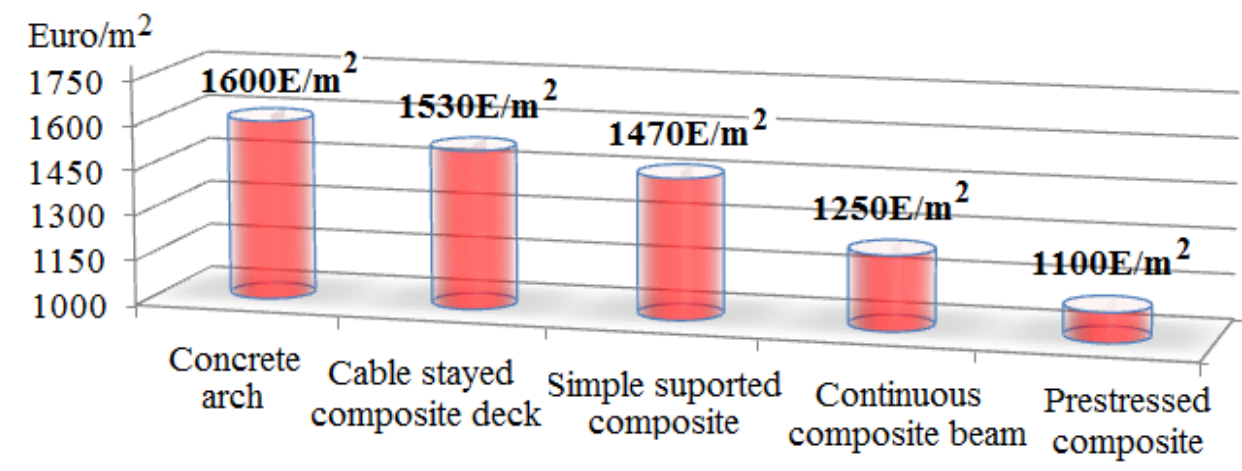

Fig. 8 - Cost $/ \mathrm{m}^{2}$ by type of structure

\section{Establishing the number and the length of the spans}

The logical conclusion is to design a composite structure with evenly distributed moment since this was the least costly per $\mathrm{m}^{2}$ (the externally prestressed composite did not satisfy the Eurocode requirements) but in the same time as short as possible. Thus, a simple supported beam with cantilevers is in order. 
The length of the left cantilever is imposed by the position of the local road while the right cantilever is kept equal to the left one in order to maintain symmetry.

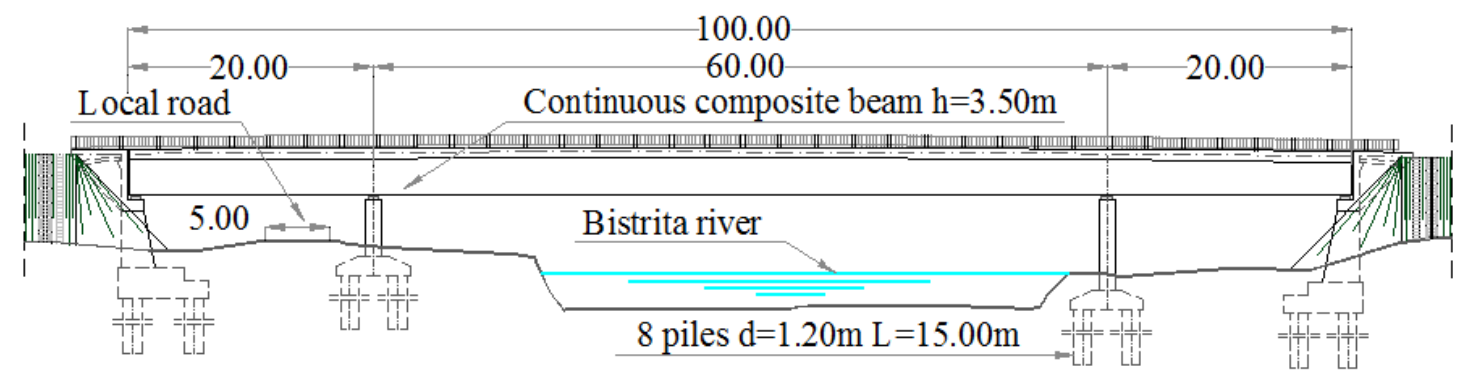

Fig. 9 - Simple supported with cantilevers composite beam

The total cost of this structure is $1,719 \mathrm{~m}$. Euro which still remains high, but looking in what the price consist of (figure 10) we find that it has a high potential for further improvement since only $22 \%$ are fixed costs and the other $78 \%$ are comprised of the structural steel $48 \%$ and foundations $30 \%$, which are both highly optimizable. The cost per $\mathrm{m}^{2}$ is $1.422 \mathrm{E}$ (above average, see figure 1).

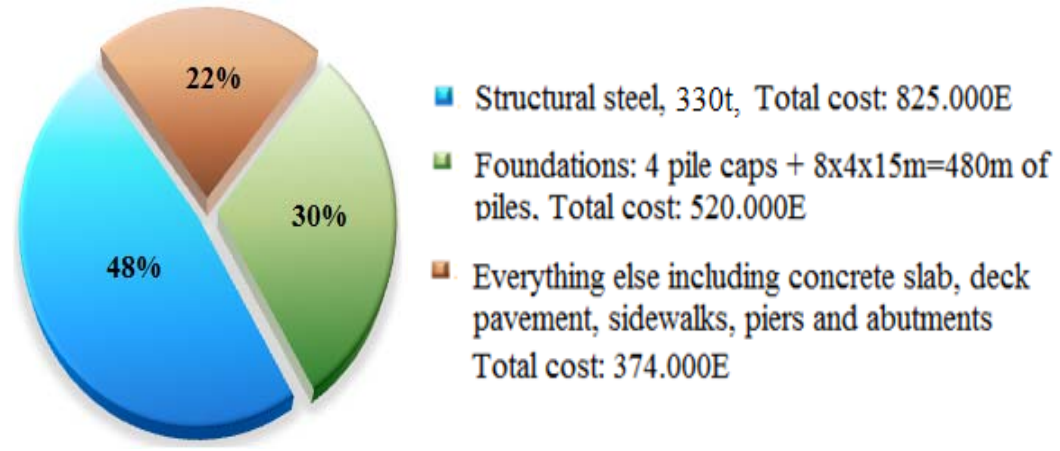

Fig. 10 - Composition of the total cost

\section{Setting the static scheme}

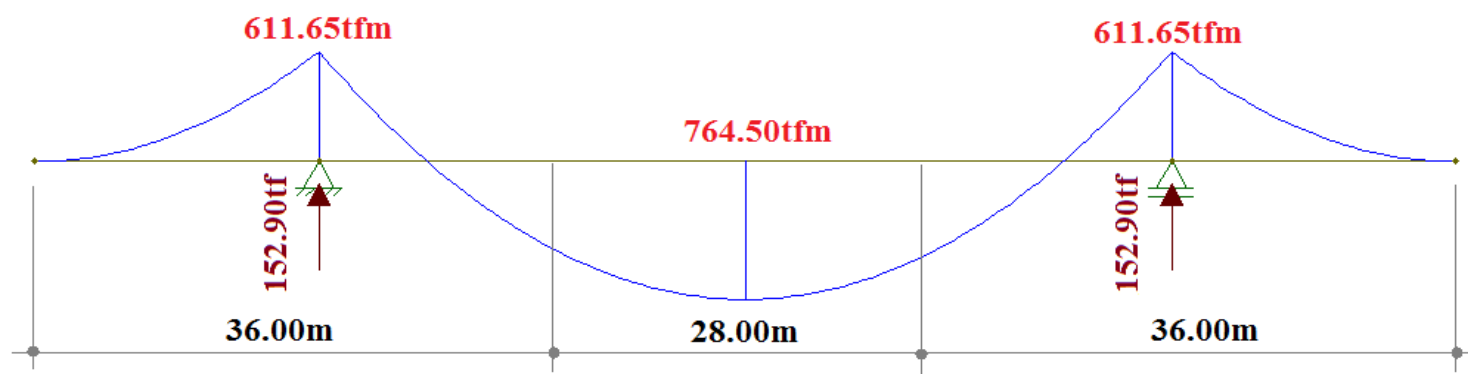

Fig. 11 - Bending moment of simple supported beam with cantilevers

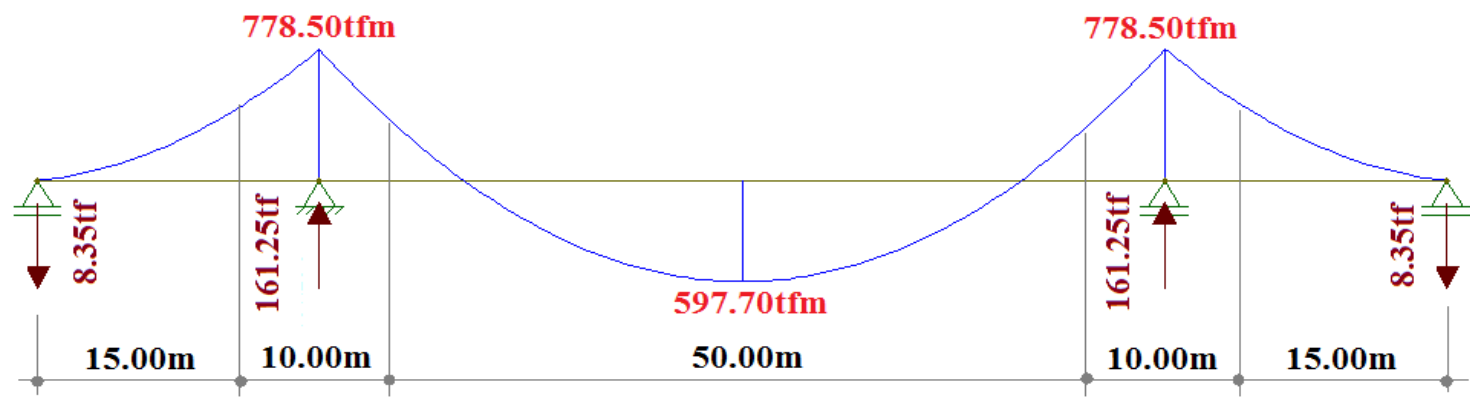

Fig. 12 - Bending moment of continuous beam with negative end reactions 


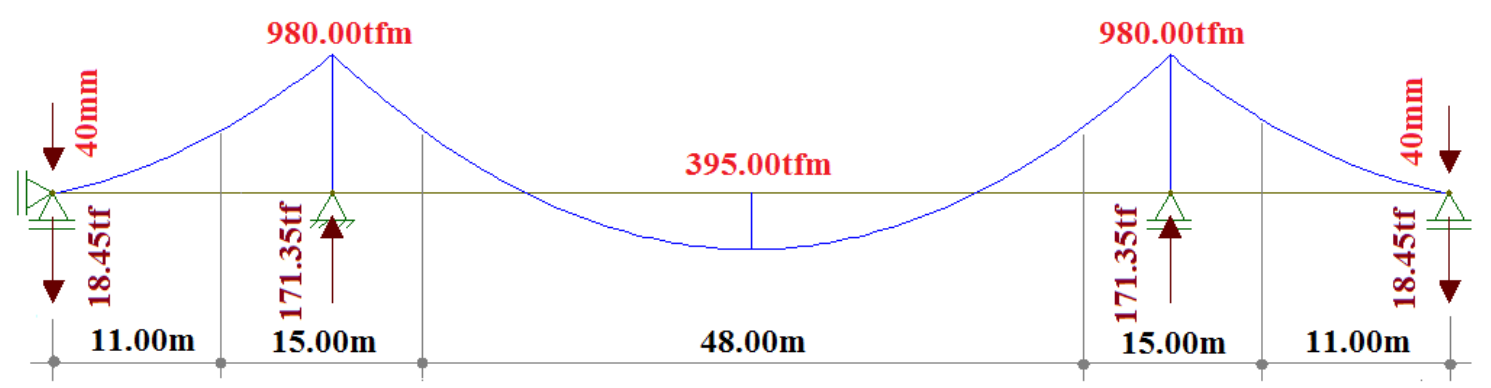

Fig. 13 - Moment of continuous beam with induced bearing displacement

From these 3 possible static schemes the most efficient is the one with $40 \mathrm{~mm}$ induced bearing displacement because it concentrates the moment in the intermediate support area which is very short in length since it dissipates very fast because the geometry of the diagram. This is shown in figures 11, 12 and 13 .

Assuming that only 2 types of cross sections are utilized throughout the length, then:

$$
\begin{aligned}
& M_{\text {tot1 }}=2 \cdot 36 \mathrm{~m} \cdot 611,65 \mathrm{tfm}+28 \mathrm{~m} \cdot 764,50 \mathrm{tfm}=65472,8 \mathrm{tfm} \cdot \mathrm{m} \\
& M_{\text {tot2 }}=(2 \cdot 15 \mathrm{~m}+50 \mathrm{~m}) \cdot 597.7 \mathrm{tfm}+20 \mathrm{~m} \cdot 778,5 \mathrm{tfm}=63386 \mathrm{tfm} \cdot \mathrm{m} \\
& M_{\text {tot3 }}=(2 \cdot 11 \mathrm{~m}+48 \mathrm{~m}) \cdot 395 \mathrm{tfm}+30 \mathrm{~m} \cdot 980 \mathrm{tfm}=53100 \mathrm{tfm} \cdot \mathrm{m}
\end{aligned}
$$

where: $\mathrm{M}_{\mathrm{tot1}}, \mathrm{M}_{\mathrm{tot} 2}, \mathrm{M}_{\mathrm{tot} 3}$ are values that represent the overall bending moment on the entire beam for the 3 respective static schemes in respective order.

\section{Determining the optimal cross section of the steel beams}

After choosing the static scheme 2 types of cross sections resulted, one type for the support which extends over a length of $2 \times 15=30 \mathrm{~m}$ and another type for the mid span which extends over a length of $2 \times 11+48=60 \mathrm{~m}$.

These configurations of the cross sections were established via the classic iterating process $[5][6][7][8]$ in which the values are changed using an educated guess until improvement is no longer possible. Another solution is to employ a mathematical optimization algorithm where the problem can be reduced to the question of what is the optimal configuration of the cross section in order to obtain the minimum area of steel while respecting the condition that the stress in the extreme inferior fiber will not exceed a certain limit. This definition is justified by the fact that the area of the concrete which is part of the composite cross section and also the upper flange can be regarded as constant values because they result from constructive and not from resistance requirements.

In the same time this line of reasoning permits to not take into consideration the stages of construction in the optimization algorithm, but instead necessitates the prior knowledge of the required value for the inferior resistance modulus $W$ of the steels section which can be obtained only after a standard dimensioning computation where the stages are taken into consideration and from where results a first configuration of the entire cross section which has the required inferior $W$ for the composite cross from where the steels required inferior $W$ is computed, this being possible because the steels $W$ will result in a proportional composite $W$ regardless of the steels moment of inertia $I$.

An example of this method using MathCad software will be presented below.

The first step is obtaining the necessary $W$ of the steels cross section, procedure which was previously discussed. This step is already accomplished in this example as the $W$ of the current cross sections are going to be used.

Area of the intermediate support cross section: Aos $=0.125 \mathrm{~m}^{2}$ 
Resistance modulus for the intermediate support: Wos $=\mathrm{I}_{\text {steel }} \mathrm{S} / \mathrm{Yos}_{\text {inf }}=0.158 \mathrm{~m}^{3}$

Area of the mid span cross section: Aom $=0.075 \mathrm{~m}^{2}$

Resistance modulus for the mid span section: Wom $=\mathrm{I}_{\text {steel }} \mathrm{m} /$ Yom $_{\text {inf }}=0.073 \mathrm{~m}^{3}$

Then the definition of the objective function that needs to be minimized, in this case the area of the steel cross section:

$$
f=h_{w e b} \cdot t_{w e b}+t_{u f} \cdot b_{u f}+t_{i f 1} \cdot b_{i f 1}+t_{i f 2} \cdot b_{i f 2}
$$

Where: $h_{\text {web }}$ and $t_{\text {web }}$ height and the thickness of the web

$t_{u f}$ and $b_{u f}$ thickness and the width of the upper flange

$t_{\text {if } 1}$ and $b_{\text {if } 1}$ thickness and width of the first inferior flange

$t_{\text {if2 }}$ and $b_{\text {if2 }}$ hickness and width of the second inferior flange

Next, initial guess values must be provided for all the dimensions that are declared in the objective function. The initial values represent the starting point in the algorithms search, so the closer they are to the solution the faster the answer will be, but of course this is not a concern for a modern computer.

Further the conditions must be stated, in this case:

$$
\begin{aligned}
& \mathrm{W}_{\text {inf }} \mathrm{s}=\mathrm{I}_{\text {steel }} \mathrm{S} / \mathrm{Cgs} \geq 0.158 \mathrm{~m}^{3} \text { for the support cross section } \\
& \mathrm{W}_{\text {inf }} \mathrm{m}=\mathrm{I}_{\text {steel }} \mathrm{m} / \mathrm{Cgm} \geq 0.073 \mathrm{~m}^{3} \text { for the mid span cross section }
\end{aligned}
$$

Where: $\mathrm{W}_{\mathrm{inf}}$ is the steels cross sections inferior modulus of resistance.

$\mathrm{I}_{\text {steel }}$ is the steels cross sections moment of inertia.

$\mathrm{Cg}$ is the position of the center of gravity from the inferior fiber.

Note that equations (5) must be declared in MathCad in extended form showing the relationship between the constituent elements of the objective function.

$$
\begin{array}{ll}
t_{\text {web }} \geq 14 \mathrm{~mm} & \text { for the support cross section } \\
t_{\text {web }} \geq 12 \mathrm{~mm} & \text { for the mid span cross section } \\
t_{\mathrm{uf}} \geq 20 \mathrm{~mm} & \text { the thickness of the upper flange } \\
b_{\mathrm{uf}} \geq 400 \mathrm{~mm} & \text { the width of the upper flange } \\
1200 \mathrm{~mm} \geq \mathrm{t}_{\text {if } 1} \geq 500 \mathrm{~mm} & \text { width of the first inferior flange } \\
50 \mathrm{~mm} \geq \mathrm{b}_{\text {if } 1} \geq 15 \mathrm{~mm} & \text { thickness of the first inferior flange } \\
b_{\text {if } 1}-100 \mathrm{~mm} \geq \mathrm{b}_{\text {if } 2} \geq 500 \mathrm{~mm} & \text { width of the second inferior flange } \\
50 \mathrm{~mm} \geq \mathrm{b}_{\text {if } 2} \geq 15 \mathrm{~mm} & \text { thickness of the second inferior flange }
\end{array}
$$

Ultimately calling a MathCad solver [9]. MathCad software has several solvers and several algorithms to solve an optimization, each of them having advantages and disadvantages over one another. We found that 'Minimize' solver performs best for this particular type of problem. 'Minimize' solver can employ 3 non-linear optimization algorithms, namely LevenbergMarquardt, Conjugate Gradient and Quasi-Newton from which it chooses automatically.

$$
V=\operatorname{Minimize}\left(f, h_{w e b}, t_{w e b}, t_{u f}, b_{u f}, t_{i f 1}, b_{i f 1}, t_{i f 2}, b_{i f 2}\right)
$$


Where: $\mathrm{V}$ is the results vector with the optimized dimensions in the columns

$$
\begin{aligned}
& \mathrm{Vs}=(3000,14,20,400,40,1200,11,1100) \mathrm{mm} \\
& \mathrm{Vm}=(2500,12,20,400,25,1200,0,0) \mathrm{mm} \\
& A_{o} s=f\left(V_{0}, V_{1}, V_{2}, V_{3}, V_{4}, V_{5}, V_{6}, V_{7}\right)=0.109 \mathrm{~m}^{2} \\
& A_{o} m=f\left(V_{0}, V_{1}, V_{2}, V_{3}, V_{4}, V_{5}, V_{6}, V_{7}\right)=0.067 \mathrm{~m}^{2}
\end{aligned}
$$

For the support section

For the mid span section

Area of the support section

Area of the mid span section

\section{Setting the longitudinal beam geometry}

After the optimization a choice has to be made whether to maintain the beams height constant or to make it variable. The downside of variable height is the increased cost of execution, but in recent years, thanks to developments in technology this is no longer relevant when compared to the possible reductions in steel consumption. On the other hand, variable height not only allows the configurations resulted from the optimization, but further concentrates the bending moment in the intermediate support area which was shown to be favorable. Thus, the variable height solution is chosen, which in turn gives rise to a recurrent calculation of all the steps above which results in a $3.00 \mathrm{~m}$ height for the intermediate support cross section and a $1.50 \mathrm{~m}$ for the mid span section.

\section{Establishing the number of beams in the cross section}

Computations were made with 2, 3 and 4 beams in the cross section. The conclusion being that increasing the number of beams only increases the steel consumption (figure 16) and only decreases the reinforcement in the concrete deck which is negligible for the total cost, but not the volume of the concrete.

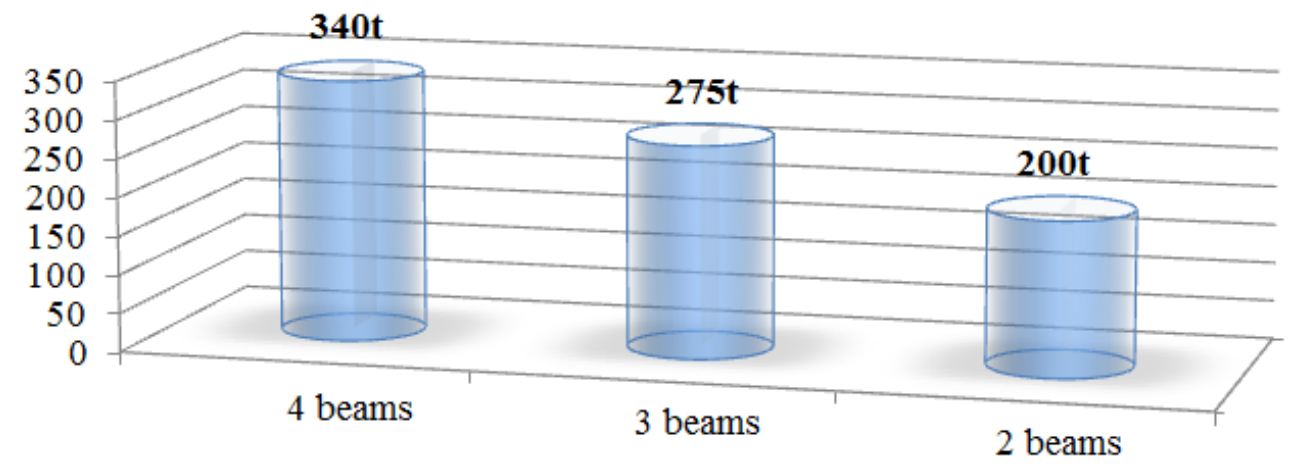

Fig. 16 - Comparison of 2, 3 and 4 beams in section by the steel consumption

\section{Determining the mounting order of the concrete slabs}

By mounting the concrete slabs in the intermediate support area first the advantage is double, primarily when mounting the concrete slabs in the mid span which produces most of the bending moment in this stage of construction both at support and at the mid span the intermediate support area will be composite, thus reducing the steel requirement and secondly also because when mounting the mid span the support section will be composite it will further concentrate the moment in the support area. $20 \mathrm{t}$ were reduced in this example.

\section{Establishing the optimal type and distribution of the bearing devices}

The bearing devices play an important role in the infrastructures configuration since they dictate the structures response to the seismic actions. A very efficient scheme in 3 span bridge structures is to concentrate most of the seismic energy in a single abutment because its elevation is already massive enough from constructive purposes and regarding the foundation its resistance increases 
exponentially with the distance between its piles while on the other hand the seismic energy intake increases linearly with the decupling of another infrastructure. For example, in the present case, this was accomplished by maintaining a neoprene bearing device on the left abutment while mounting steel bearings on the other 3 infrastructures which allow free movement in the horizontal plane. This configuration resulted in the elimination of all the piles on the three infrastructures with steel bearings while only a $3.00 \mathrm{~m}$ increase in the distance between the piles was necessary for the left abutment in order to safely dissipate the whole earthquake energy.

\section{Conclusions}

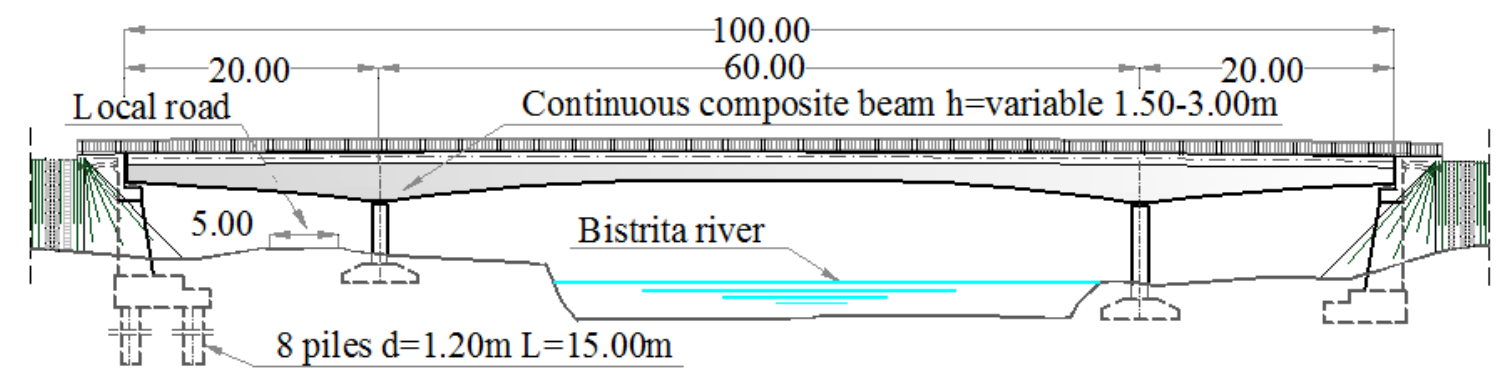

Fig. 17 - Final bridge design

The total cost resulted is 1.064.730 Euro while the cost per $\mathrm{m}^{2}$ is 875 Euro which represents a $34 \%$ reduction as against the mean value (figure 1 ). The steel quantity is $180 \mathrm{t}$ while the first proposal had 330t of steel (figure 9 and 10).

\section{References}

[1] IPTANA. Studiu de fezabilitate Varianta optima de construire autostrada Ditrau-Targu Neamt. Contract no. 92/58623/4275.

[2] IPTANA (2009). Asistenta tehnica pentru elaborarea studiului de fezabilitate, proiectului tehnic si a detaliilor de executie pentru variantele de ocolire Bistrita, Gheorghieni si Miercurea Ciuc. Contract no. 2/1/001/002.

[3] Alain Nussbaumer, Luis Borges, Laurence Davaine (2011). Fatigue design to steel and composite structures. Berlin. Ernst \& Sohn.

[4] ASRO (2006). SR EN 1993-1-1 Eurocod 3: Proiectarea structurilor de oţel. Bucharest.

[5] ASRO (2004). SR EN 1994-1-1 Eurocod 4: Proiectarea structurilor compozite de oţel şi beton. Bucharest.

[6] Laurence Davaine, Florent Imberty, Joel Raoul (2007). Guidance book Eurocodes 3 and 4 - Application to steelconcrete composite road bridges. Fance. Service d'études techniques des routes et autoroutes - Sétra.

[7] C.R.Hendy, R.P.Jhonson (2006). Designers guide to EN 1994-2 - Design of steel and composite structures. London. Thomas Telford.

[8] Darko Beg, Ulrike Kuhlmann, Laurence Davaine (2011). Design of plated structures. Berlin. Ernst \& Sohn.

[9] (2007). MATHCAD, version 14.0 [computer software]. MA, USA. Parametric Technology Corporation. 